\title{
Searching for the Lost Ostium: A Morphometric Analysis of the Ureteral Ostia Distribution in Normal and Thickened Bladders and Its Applications in Endourology
}

\author{
Mariana Greco, Paula Marsillac, Julia Vieira, Mario Brito, Andre Saud, \\ Rafael Prinz, Joao Pereira-Correia* \\ Department of Anatomy, Faculty of Medicine, Estácio de Sá University, Rio de Janeiro, Brazil

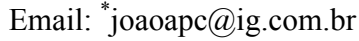

Received May 12, 2013; revised June 10, 2013; accepted June 18, 2013

Copyright (C) 2013 Mariana Greco et al. This is an open access article distributed under the Creative Commons Attribution License, which permits unrestricted use, distribution, and reproduction in any medium, provided the original work is properly cited.

\begin{abstract}
Introduction: The ureteral ostia may not be easily identified in urological endoscopic procedures, leading to an incomplete diagnosis of urinary tract diseases or a predisposition to iatrogenic lesions. The purpose of our study is to evaluate the anatomical distribution of ureteralostia in normal bladders and those with thickened walls. Materials and Methods: We dissected 30 vesical-prostate blocks from human cadavers and identified the ostia of the bladder trigone. A computerized morphometric analysis was performed to measure the thickness of the detrusor muscle, the distances between the ureteral ostia themselves and the distances between each ureteral ostium (left-LUO and right-RUO) and the internal urethral ostium (IUO). The angle formed between the IUO and LUO/RUO was also recorded as well as the volume of the prostates. Results: Fifteen bladders with a non-thickened detrusor $(<5 \mathrm{~mm})$ as well as 15 bladders with muscular thickening $(>6 \mathrm{~mm})$ were identified. The average prostatic volume of the dissected blocks was $23.7 \mathrm{~cm}^{3}$. The distance between ureteral ostia, the distance from IUO to LUO, the distance from IUO to RUO and the angle formed between IUO and LUO/RUO in normal and thickened bladder were, respectively, $1.9 \mathrm{~cm} / 2.2 \mathrm{~cm}(\mathrm{p}=0.09), 1.6 \mathrm{~cm} / 1.6 \mathrm{~cm}(\mathrm{p}=$ $0.82), 1.6 \mathrm{~cm} / 1.7 \mathrm{~cm}(\mathrm{p}=0.79)$ and $77 / 91(\mathrm{p}=0.17)$. Conclusions: Our study shows that there is no significant difference in the position of bladder ostia in healthy and thickened bladders. We believe that our findings may facilitate locating the ureteral orifices in situations where endoscopic identification is difficult.
\end{abstract}

Keywords: Ureteral Orifice; Cystoscopy; Bladder; Anatomy; Internal Urethral Orifice; Transurethral Resection of the Prostate; Transurethral Resection of Bladder Tumor

\section{Introduction}

Endoscopic procedures involving the bladder are of great value to urological medical practice, both for diagnostic and therapeutic purposes. These include cystoscopy, retrograde pyelography, and bladder/prostatic resections. When these are performed, however, the ureteral ostia may not be easily identified, leading to an incomplete diagnosis of urinary tract diseases or a predisposition to iatrogenic lesions [1,2]. The outcome of inadvertent injury to the ureteral orifices varies, ranging from the development of stricture and upper tract hydronephrosis, to simple reflux with no long-term damage [3-6].

Surgeries that promote infravesical obstruction by re-

${ }^{*}$ Corresponding author. ducing prostatic volume deserve special attention. As the male population continues to age, these procedures are becoming more common [7,8]. Endoscopic techniques that are considered minimally invasive range from traditional transurethral resection to laser photovaporization of the prostate, are recommended in main urological guidelines $[9,10]$. In these patients, it is not uncommon to observe thickening of the detrusor muscle as a result of an infravesical obstruction [11,12]. Surprisingly, there are few studies to date that have evaluated how ureteral ostia are distributed in this bladder's new state.

Most of the information available regarding the morphometric aspects of ureteral ostia still originates from classical anatomy texts, and the few studies that are available have only explored vesicoureteral reflux in pediat- 
ric patients $[13,14]$. Therefore, in this study we evaluated the anatomical distribution of ureteral ostia in normal bladders and those with thickened walls.

\section{Materials and Methods}

We dissected vesical-prostate blocks from human cadavers preserved in a 5\% formaldehyde solution. The cadavers were obtained from the anatomy laboratory of the Faculty of Medicine at the Estácio de Sá University after study approval from the institutional Research and Ethics Committee. We obtained the epidemiological data for each cadaver from the respective death certificates.

We excluded cadavers where the cause of death or identifiable comorbidities on the certificate involved vesical compromise, such as bladder cancer, cancer of the adjacent pelvic organ, genitourinary tuberculosis, neurogenic bladder, diabetes mellitus, or collagen disease, among others. In addition, we excluded bladders that showed macroscopic changes or elevation of the vesical's floor as a result of an increase in the global prostatic volume or the volume of one of the prostate's lobes.

We performed vesical dissection through a median infra-umbilical incision, in layers, up to the bladder and the prostate. After sectioning the endopelvic fascia and puboprostatic ligaments, we withdrew the vesical-prostate block from the pelvis, adopting a similar technique as the modified radical cystoprostatectomy proposed by Schlegel and Walsh [15]. We proceeded with a horizontal incision, in the anteroposterior direction, of the bladder superior wall to identify the ureteral ostia and the internal urethral orifice.

We identified the ostia of the vesicaltrigone using colored pins and the following markings: the right ureteral ostium (RUO) with green pins, the left ureteral ostium (LUO) with blue pins, and the internal urethral ostium (IUO) with pink pins (Figure 1). Next, we photographed the anatomical specimens using a 14.1 megapixel highresolution digital camera (Sony $^{\mathrm{TM}}$ Cyber-Shot ${ }^{\mathrm{TM}}$ DSCW320, Sony Corp., Tokyo, Japan).

We used the Image Pro Plus ${ }^{\mathrm{TM}}$ software, version 4.5, from Media Cybernetics ${ }^{\mathrm{TM}}$ (Bethesda, MD, USA) for the morphometric analysis. We measured the distances between the ureteral ostia themselves and the distances between each ureteral ostium and the internal urethral ostium. The angle formed between the IUO and the LUO/ RUO was also recorded. Using the same software, we measured the thickness of the detrusor muscle of the wall of each bladder at three different points: the region with the least thickness, the region of intermediatethickness, and the region with the greatest thickness. Based on these measurements, we calculated the "average" detrusor thickness for each dissected specimen. Finally, we measured each prostate on three axes (cranio-caudal, laterolateral, andanteroposterior). After multiplying the three

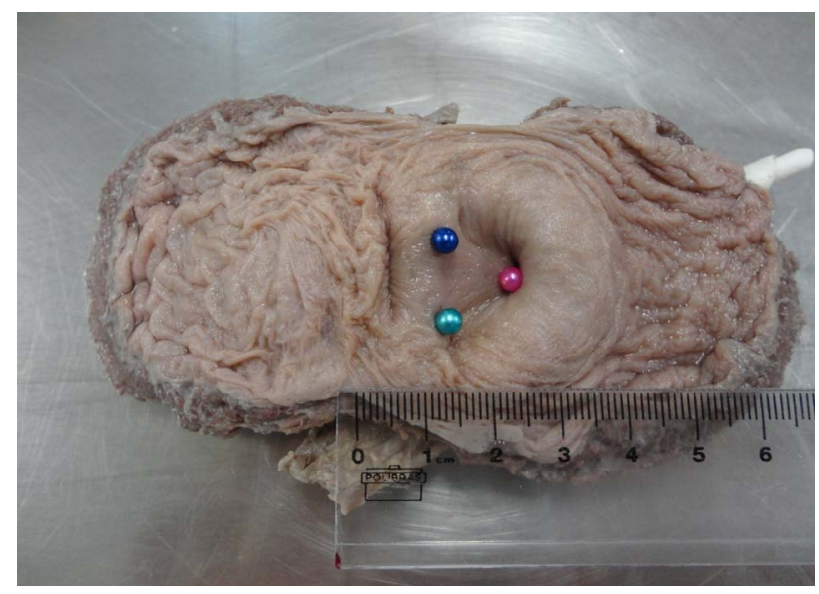

Figure 1. Dissected bladder showing the vesicaltrigone, with colored pins in the ureteral and urethral orifices: right ureteral ostium with a green pin, left ureteral ostium with a blue pin, and internal urethral ostium with a pink pin.

measurements, we obtained the volume for each gland.

Based on a study by Manieri et al. [16] that compared dynamic vesical ultrasound to uroflowmetry and pressure-flow study, we considered a value of up to $5 \mathrm{~mm}$ as a "normal" detrusor thickness and a detrusor thickness greater than $6 \mathrm{~mm}$ as "thickened".

Statistical analysis of the results was performed using GraphPad Prism ${ }^{\mathrm{TM}}$, version 5 (La Jolla, CA, USA). The Kolmogorv-Smirnov test was used to evaluate normality. For data with a Gaussian distribution, we performed a comparative evaluation of the groups using a Student's $t$ test. For data with a non-Gaussian distribution, we used the Mann-Whitney test. Data with a $\mathrm{p}<0.05$ were considered statistically significant.

\section{Results}

We dissected 30 vesical-prostate blocks. The cadavers' ages ranged between 48 and 76 years (average: 62 years). All were Brazilians, with 20 of them being of African heritage and 10 of them Caucasian. The average prostatic volume of the dissected blocks was $23.7 \mathrm{~cm}^{3}$ (range: 7.9 to $47.6 \mathrm{~cm}^{3}$ ). The detrusor muscle thickness ranged from 2 to $11 \mathrm{~mm}$ (average: $5 \mathrm{~mm}$ ), and we identified 15 bladders with a non-thickened detrusor $(<5 \mathrm{~mm})$ as well as 15 bladders with muscular thickening $(>6 \mathrm{~mm})$.

\section{Discussion}

The preoccupation with the arrangement of ureteral ostia dates from the middle of the nineteenth century when Desormeaux, in 1853, first introduced an endoscopic device capable of visualizing the bladder, according to a recent historical review [17]. In his classic encyclopedia "The International Encyclopedia of modern Medical Science by leading authorities of Europe and America," 
Stedman also noted that, "the ability to find the ureter readily is developed by practice..." but that "... occasionally the bladder presents some little depression which the examiner cannot be sure is not the ureteral orifice" [18].

The first descriptions of the position of the ureteral ostia, with clinical application, occurred in the area of Uropediatrics. The classical study by Lyon et al. proposed classifying these ostia, as well as their location, in terms of their morphological appearance [19]. Ostia near the median line received a "type A" classification, whereas ostia that were more distant from the median line, almost in the lateral walls of the bladder, received a "type C" classification. Ostia in an intermediate position were classified as "type B." The authors observed that the further the ostia are from the median line (type C), the greater the chance of vesicoureteral reflux and, as a consequence, the greater the likelihood that girls will suffer repeated incidences of urinary tract infection. Nearly forty years later, Yucel et al. observed that ureteral ostia in a more lateral position can even affect the success rates of endoscopic surgery using injectable agents in an effort to correct vesicoureteral reflux in children [14]. The study with 26 girls and 20 boys found that $60 \%$ of children with ostia distributed in a "type C" position had an unsuccessful surgery.

However, only considering the position of the ostia in relation to the median line without precise measurements might be too empirical, because this approach has the risk of underestimating the prognostic use as well as preoperative planning of vesicular endoscopic interventions 20 . Without a more precise indication of the location of ureteral ostia, it is possible to cause unnecessary trauma to the bladder or even inadvertent resectioning of it during diagnostic and/or therapeutic procedures [3-6]. Mano et al. reported dramatic consequences for patients undergoing iatrogenic resection of the ureteral ostium during transurethral resection of a bladder tumor, and the authors referred to the need for a ureteral reimplant for persistent stenosis, surgical nephrostomy, and even definitive loss of kidney function in some cases [20].

The descriptions in classic textbooks dedicated to the study of pelvic anatomy show that the distance between ureteral ostia usually varies from 2 to $3 \mathrm{~cm}$, whereas the distance between them and the internal urethral ostium remains at $2 \mathrm{~cm}$ [21-23]. In a post-mortem study before fixation of 239 Australian children and adolescents, Cussen observed a gradual increase in the distance between the ostia and the bladder neck as an individual grows [24]. In 166 newborns, this measurement averaged 1.2 $\mathrm{cm}$; in older subjects between the ages of 12 and 18, it averaged $2.3 \mathrm{~cm}$. Cussen observed the same proportions when evaluating these measurements in relation to the group's weight and height; however, our study identified shorter lengths. The distance from the bladder neck to the entrance of the ureter averaged $1.6 \mathrm{~cm}$, and the two structures were approximately $2 \mathrm{~cm}$ apart. It is possible that the larger measurements identified in other studies are related to different anthropometric peculiarities, since, for instance, the average height of Australians is approximately $5 \mathrm{~cm}$ greater than that for Brazilians [25,26]. Thus, studies that take into consideration anthropometric parameters, such as weight and height as well as age range, are still needed to test this hypothesis.

One weakness of our study arises from the fact that we evaluated bladders fixed in formaldehyde and, as a result, they may have suffered tissue shrinkage [27]. Studies on patients undergoing cystoscopy, however, have yielded results similar to ours, indicating that shrinkage most likely does not have much influence on these measurements. Perks et al. evaluated 10 male patients and 11 female patients undergoing an endoscopic vesical examination and found that the average distance between the bladder neck and the ureteral ostia was $1.8 \mathrm{~cm}$ in men and $2.0 \mathrm{~cm}$ in women [28].

Another weakness of this study was that the distribution of ostia was analyzed on the empty bladders of cadavers in a supine position. Bladder endoscopy is performed with the patient in a lithotomy position (dorsal decubitus together with abducting and flexing of the thighs) and bladder distension, which is a position that could alter the location of ureteral orifices. The distance between the ureteral ostia doubles from $2.5 \mathrm{~cm}$ to $5 \mathrm{~cm}$ in full bladders, according to Williams et al. [23]. Perks et al. describe an average increase of $1 \mathrm{~cm}$ in distance between the bladder neck and the ureteral ostia after filling [28]. Despite the change in the location of the ostia that dynamic studies of the bladder have shown, we do not believe that such a condition discredits the clinical applicability of our findings because during endoscopic exams, it is possible to empty the bladder in direct view and to examine it in this state in case of difficulty in locating the ureteral orifices. In addition, any change in the position of these orifices, in terms of the position adopted by the patient for vesicular endoscopic evaluation, does not seem significant. Studies based on intraoperative fluoroscopic evaluation of the bladder show that there is no statistically significant difference in the location of the ureteral openings with respect to the bladder neck when the lithotomy position is adopted [28].

The angle formed between the internal urethral ostium and the ureteral ostia found in our study was $84^{\circ}$. Hatano et al. described similar findings for this measurement in a study on patients who had undergone a cytoscopic evaluation, with a value equivalent to $81.5^{\circ}$ [29]. However, we verified that there is little description of this measurement in anatomical and endoscopic studies of the bladder. We believe that knowing the angle between the 
bladder neck and the ureteral openings as well as the distances between these ostia could facilitate locating them in situations where intraoperative identification is difficult, since, in theory, it is relatively easy to measure this angulation with a cytoscope or resectoscope during endoscopic procedures.

In conclusion, we would like to emphasize the pioneering nature of our research regarding the influence of detrusor muscle thickness on locating ureteral ostia. Despite the difficulties in establishing a value for the thickness of the vesicular detrusor muscle, which would function as one of the diagnostic signs of infravesical obstruction in men, recent ultrasound studies suggest $5 \mathrm{~mm}$ as the maximum normal value for detrusor thickness [16, 30,31]. Based on this value, we identified 15 thickened bladders and 15 non-thickened bladders in our study cohort. We measured the detrusor at three different points on the wall of the vesical (least thickness, intermediate thickness, greatest thickness) to increase the reliability of our results. Nevertheless, we did not observe a statistically significant difference in terms of the position of the ureteral orifices and the angle formed between them and the internal urethral ostium in any of the samples. This finding is important, as a large number of transurethral resection surgeries of the prostate are performed on thickened bladders as a result of an obstruction caused by benign prostatic increase [32]. Our results suggest that the distances observed in healthy bladders can also be used on these patients if it becomes difficult to locate the ureteral ostia during surgery. Nevertheless, additional studies using a larger sample size are needed that are performed during prostate resection surgery in order to make a definitive conclusion regarding this matter.

\section{Conclusion}

We believe that knowing the angle between the bladder neck and the ureteral openings as well as the distances between these ostia could facilitate locating them in situations where intraoperative identification is difficult. Our results also suggest that the distances observed in healthy bladders can also be used during endoscopic procedures on thickened bladders as well.

\section{REFERENCES}

[1] V. O'Conor, "Bilateral Intramural Strictures of the Ureters after Transurethral Resection of the Prostate," Journal of the American Medical Association, Vol. 145, No. 16, 1951, pp. 1249-1251. doi:10.1001/jama.1951.02920340027008

[2] J. Davis, "Ureteral Injury by Transurethral Electroresection and Coagulation," Journal of Urology, Vol. 68, No. 1, 1952, pp. 168-177.

[3] R. Rees, "The Effect of Transurethral Resection of the
Intravesical Ureter during the Removal of Bladder Tumours," British Journal of Urology, Vol. 41, No. 1, 1969 , pp. 2-5. doi:10.1111/j.1464-410X.1969.tb09900.x

[4] B. Posta, B. Streit and J. Schmauzer, "Transurethral Resection of the Carcinomatous Ureteral Orifice: Analysis of 27 Operations," International Urology and Nephrology, Vol. 12, 1980, pp. 23-35. doi:10.1007/BF02085378

[5] A. Gottfries, S. Nilsson, T. Sundin, et al, "Late Effects of Transurethral Resection of Bladder Tumours at the Ureteric Orifice," Scandinavian Journal of Urology, Vol. 9, No. 1, 1975, pp. 32-35. doi:10.3109/00365597509139910

[6] L. Kisbenedek, P. Szeldeli, G. Biró, et al., "Vesicoureteral Reflux Following Transurethral Resection of Bladder Tumours at the Ureteral Orifice," European Urology, Vol. 8, 1982, pp. 9-10.

[7] A. Tubaro and C. Nunzio, "The Current Role of Open Surgery in BPH," EAU-EBU Update Series, Vol. 4, No. 5, 2006, pp. 191-201. doi:10.1016/j.eeus.2006.07.002

[8] J. Mandeville, E. Gnessin and J. Lingeman, "New Advances in Benign Prostatic Hyperplasia: Laser Therapy," Current Urology Reports, Vol. 12, No. 1, 2011, pp. 5661. doi:10.1007/s11934-010-0153-1

[9] K. McVary, C. Roehrborn, A. Avins, et al., "American Urological Association Guideline: Management of Benign Prostatic Hyperplasia (BPH)," AUA Guidelines, 2010, pp. 1-27.

[10] M. Oelke, A. Bachmann, A. Descazeaud, et al., "Guidelines on the Management of Male Lower Urinary Tract Symptoms (LUTS), incl. Benign Prostatic Obstruction (BPO)," EAU Guidelines, 2012, pp. 1-74.

[11] J. Dixon, C. Gilpin, S. Gilpin, et al., "Sequential Morphological Changes in the Pig Detrusor in Response to Chronic Partial Urethral Obstruction," British Journal of Urology, Vol. 64, No. 4, 1989, pp. 385-390. doi:10.1111/j.1464-410X.1989.tb06048.x

[12] M. Oelke, K. Hofner, B. Wiese, et al., "Increase in Detrusor Wall Thickness Indicates Bladder Outlet Obstruction (BOO) in Men," World Journal of Urolog, Vol. 19, No. 6, 2002, pp. 443-452.

[13] F. Deture and R. Walker, "Measurement of the Distance from the Ureteral Orifice to the Bladder Neck: Additional Objective Data in the Cystoscopy of Patients with Reflux," Journal of Urology, Vol. 112, 1974, pp. 326-328.

[14] S. Yucel, M. Ucar, E. Guntekin, et al., "The Effect of Location of the Ureteric Orifice on the Efficacy of Endoscopic Injection to Correct Vesico-Ureteric Reflux," BJU International, Vol. 95, No. 9, 2005, pp. 1314-1318. doi:10.1111/j.1464-410X.2005.05525.x

[15] P. Schlegel and P. Walsh, "Neuroanatomical Approach to Radical Cystoprostatectomy with Preservation of Sexual Function," Journal of Urology, Vol. 138, No. 6, 1987, pp. 1402-1406.

[16] C. Manieri, S. Carter, G. Romano, et al., "The Diagnosis of Bladder Outlet Obstruction in Men by Ultrasound Measurement of Bladder Wall Thickness," Journal of Urology, Vol. 159, No. 3, 1998, pp. 761-765. doi:10.1016/S0022-5347(01)63723-6

[17] M. Samplaski and J. Jones, "Two Centuries of Cysto- 
scopy: The Development of Imaging, Instrumentation and Synergistic Technologies," BJU International, Vol. 103, No. 2, 2009, pp. 154-158. doi:10.1111/j.1464-410X.2008.08244.x

[18] T. Stedman, "Methods of Examining the Female Urinary Organs," In: Twentieth Century Practice: An International Encyclopedia of Modern Medical Science by Leading Authorities of Europe and America, W. Wood and Company Inc., New York, 1895, pp. 235-237.

[19] R. Lyon, S. Marshall and E. Tanagho, "The Ureteral Orifice: Its Configuration and Competency," Journal of Urology, Vol. 102, No. 4, 1969, pp. 504-509.

[20] R. Mano, O. Shoshany, J. Baniel, et al., "Resection of Ureteral Orifice during Transurethral Resection of Bladder Tumor: Functional and Oncologic Implications," Journal of Urology, Vol. 188, No. 6, 2012, pp. 2129-2133. doi:10.1016/j.juro.2012.08.006

[21] A. Bouchet and J. Cuilleret, "L'abdomen, la RégionrétroPéritonéale, le Petit Bassin, le Périnée," In: Anatomietopographique: Descriptive Etfonctionnelle, Masson Inc., Paris, 1997, pp. 140-154.

[22] L. Costacurta, "Aspectos da Anatomia Aplicada da Bexiga Urinária," In: Anatomia Médico-Cirúrgica da Pelve Humana, Atheneu Inc., São Paulo, 1982, pp. 101-111.

[23] P. Williams, R.Warwick, M. Dyson, et al., "A Bexiga Urinária," In: Gray's Anatomy, Guanabara Koogan Inc., Rio de Janeiro, 1989, pp. 1334-1337.

[24] L. Cussen, "Normal Position of the Ureteral Orifice in Infancy and Childhood: A Quantitative Study," Journal of Urology, Vol. 121, 1979, pp. 646-647.

[25] Australian Bureau of Statistics, "The Average Australian -Mean Measured Height by Age and Sex, 1995 and 2007-08," 2011.

http://www.abs.gov.au/ausstats/abs@.nsf/Lookup/4841.0 Chapter22011

[26] Brazilian Institute of Geography and Statistics (Instituto Brasileiro de Geografia e Estatística-IBGE), "Dados Amostrais e Estimativas Populacionais das Medianas de
Altura e Peso, por Situação do Domicílio e Sexo, Segundo a Idade e os Grupos de Idade Brasil-Período 2008-2009," 2010.

http://www.ibge.gov.br/home/estatistica/populacao/condi caodevida/pof/2008_2009_encaa/tabelas_pdf/tab1_1.pdf

[27] S. Jonmarker, A. Valdman, A. Lindberg, et al., "Tissue Shrinkage after Fixation with Formalin Injection of Prostatectomy Specimens," Virchows Archiv, Vol. 449, No. 3, 2006, pp. 297-301. doi:10.1007/s00428-006-0259-5

[28] A. Perks, T. Schuler, K. Pace, et al., "Prospective Determination of Ureteral Orifice Location: A Guide for Fluoroscopic Ureteral Stent Insertion," Journal of Endourology, Vol. 22, 2008, pp. 1203-1207. doi:10.1089/end.2008.0048

[29] T. Hatano, M. Hayakawa, Y. Koyama, et al., "New 3Dimensional Mapping Device for Cystoscopy," Journal of Urology, Vol. 158, No. 3, 1997, pp. 872-874. doi:10.1016/S0022-5347(01)64345-3

[30] E. Bright, M. Oelke, M. Tubaro, et al., "Ultrasound Estimated Bladder Weight and Measurement of Bladder Wall Thickness-Useful Noninvasive Methods for Assessing the Lower Urinary Tract?' Journal of Urology, Vol. 184, No. 5, 2010, pp. 1847-1854. doi:10.1016/j.juro.2010.06.006

[31] G. Franco, C. De Nunzio, C. Leonardo, et al., "Ultrasound Assessment of Intravesical Prostatic Protrusion and Detrusor Wall Thickness-New Standards for Noninvasive Bladder Outlet Obstruction Diagnosis?" Journal of Urology, Vol. 183, No. 6, 2010, pp. 2270-2274.

doi:10.1016/j.juro.2010.02.019

[32] T. Huang, J. Qi, Y. Yu, et al., "Predictive Value of Resistive Index, Detrusor Wall Thickness and Ultrasound Estimated Bladder Weight Regarding the Outcome after Transurethral Prostatectomy for Patients with Lower Urinary Tract Symptoms Suggestive of Benign Prostatic Obstruction," International Journal of Urology, Vol. 19, No. 4, 2012, pp. 343-350. doi:10.1111/j.1442-2042.2011.02942.x 